NeW SkRIEs. No. 16.]

[OCTOBER, 1895.

\title{
MIND
}

\section{A QUARTERLY REVIEW}

OF

\section{PSYCHOLOGY AND PHILOSOPHY.}

\section{I.-NOTES ON THE THEORY OF VALUE.}

\section{By Profgssor Mackenzie.}

THE conception of Value has played an increasingly prominent part in recent speculation, both in Ethics and in Economics. Indeed there has been an increasing tendency to make this conception the fundamental one in all the sciences that deal with ends. Even in the science of Education the discussion of values has come to be regarded as one of the most important parts of the study. For the prominence thus given to the conception of Value, at least in departments other than that of Economics, Herbart is probably responsible to a greater extent than any other single individual; but the interest in the subject has been by no means confined to his disciples. In Economics Jevons did much to bring out the fundamental importance of the idea of Value. It has since been emphasized by such writers as Menger, Wieser, Böhm-Bawerk, \&ce, and it plays a prominent part in the writings of Wagner, Marshall, and many others. The wider bearings of the idea of Value were developed to a considerable extent by Lotze, and quite recently attention was drawn to them in this Journal in an interesting article by Professor Alexander'. I am not aware, however, that the whole subject has ever been subjected to so searching an examination as it has recently received from two Austrian writers, Alexius Meinong and Christian Ehrenfels; and

1 New Series, Vol. I., No. 1.

u. 
it is chiefly with the view of calling attention to their discussions that the present article is written ${ }^{2}$.

Ehrenfels, as I understand, must to a considerable extent be regarded as a disciple of Meinong, though he has certainly worked out his ideas in an independent and highly original way. Meinong himself has been to some extent influenced by the teaching of the psychologist Brentano ${ }^{2}$; and that both he and Ehrenfels have been a good deal affected by the elaborate discussions of their economic fellow-countrymen seems indisputable. Their views, however, do not appear to be in any way dependent on an acceptance either of the psychological position of Brentano or of the conclusions of the Austrian economists. A short account of their methods of procedure may serve as a useful introduction to such further remarks as may fall within onr present scope; but it must be distinctly understood that the value of what these two writers have put forward is very largely dependent on subtle distinctions and elaborate analyses, of which no adequate account could possibly be given in such an article as this. I can only hope that a brief indication of some of their leading positions may induce some of the readers of Mind to make a careful study of the original documents.

The views of Ehrenfels are set forth in five articles which appeared in the Vierteljahrsschrift für wissenschaftliche Philosophie for 1893 and 1894, under the title Werth-theorie und Ethik. In the first of these articles he indicates the relationship between his views and those of the Austrian economists. He agrees with the latter in holding that there is the most intimate relationship between value and utility, but that, at the same time, value does not vary directly with utility, but is dependent on marginal utility ("Grenznutzen"). In order, however, to bring out the wider bearings of the subject, he finds it necessary to introduce some distinctions which have not been recognised by the economists. Thus he distinguishes between Intrinsic and Instrumental values ("Eigenwerthe" and "Wirkungswerthe"), i.e. between objects valued for their own sakes and those valued as means of producing other valuable objects ${ }^{3}$. He also thinks it necessary to. draw a distinction

1 There are also some suggestive remarks on the subject of value in Simmel's Einleitung in die Moralwissenschaft, which has already been noticed in this Journal.

2 I judge that Ehrenfels has also been to some extent influenced by Brentano, though he is certainly far from being a disciple. In his articlo Ueber Fuihlen und Wollen (pp. 537 sqq.) he has some elaborate and penetrating criticisms of Brentano's position.

3 This distinction is not to be confounded with that commonly drawn by economists between Goods of the First and higher Orders. Economic Goods of the First Order are those that are valued for direct consumption, 
between Nutzen and Frommen. When the utility of an object is spoken of, one generally understands that its power of contributing to the happiness of some individual is referred to; and in dealing with economic goods it is seldom necessary to go beyond this. But in dealing with the wider conception of value it is necessary to have some term to express the simple choiceworthiness of an object, without reference to its power of contributing to individual happiness. Ehrenfels considers that the word "Frommen" may be conveniently used in this sense ${ }^{1}$. Hence he is led also to use the term "Grenzfrommen," or marginal advantage. He considers that the economists have tended to confine their attention too exclusively to marginal utility and to goods that have only instrumental value, and that thus their conception of value has not been sufficiently wide?

In discussing the relationship between value and utility, Ehrenfels is led to state his view with regard to the connexion between both these and the two psychological elements known as feeling and desire ${ }^{3}$ The way in which he relates the idea of value to these is specially important and interesting. $\mathrm{He}$ considers (p. 89) that value is more directly connected with

such as food, clothing, \&c., which are certainly not as a rule valued for their own sakes. On the whole it seems correct to say that all economic Goods are only of the nature of Instrumental Values. A work of art, on the other hand, has intrinsic value for the lover of the beautiful; and so has a scientific theory for the lover of truth. (Cf. Ehrenfels, loc. cit., p. 90.)

1 This distinction is rejected by Meinong ( $P^{\prime}$ sychologisch-ethische Untersuchungen zur Werth-theorie, p. 13, note) ou the ground that it is less in accordance with the usage of language than the extension of the tern Utility to cover both meanings. Certainly it would be difficult to find any; corresponding term in English to express the distinction intended by Ehrenfels; and indeed it seems to involve an inconvenient and misleading limitation in the use of the term Utility.

2 Of course the usage of the economists might be defended on the ground that it is only with these forms of value that they are specially concerned. But as Meinong points out (op. cit., p. 5, note), several economists have claimed that their discussions exhaust the whole subject of value. Thus Wieser says (Natural Value, English Translation, Preface, 1. xxxv) "I have attempted to exhaust the entire sphere of the phenomend of value without any exception." A similar clain appears to be implied in some of the statements of Menger.

3 Gefihl and Begehrung. It is important to note that Ehrenfels usen the former term in the sense that has been rendered familiar to English renders by $\mathrm{Dr}$ Ward, as including nothing but the sinple fact of being pleased and pained; while he understands the tcrm Begehrung in a wide sense, as including the whole of the active side of nind. Thus when ho speaks of desire, we must understand him to include will and also sume of those elements in mind which are commonly described as emotion (lure and hate, and the like). See his article Ceber Fühlen und Wollen, pl. 531-532. I believe this use of the term Begelurung to be sowerluat inconvenient and confusing. 
desire than with feeling. In fact he even says roundly - "This thing is valuable for me is as much as to say: This thing is an object of my desire. Value is the relation of a thing to a human desire directed towards it-a relation which receives from language an erroneous objectification." The force of this de finition is, however, a good deal modified by the subsequent remark (p. 209) that "by desire is to be understood not exclusively an actual desire, but also a possible desire, or, what is the same thing, a tendency to desire." This view of Ehrenfels does not entirely meet with Meinong's approval ${ }^{1}$; and certainly it seems open to serious objection. It appears at least, on the face of it, to ignore the importance of Dr Sidgwick's famous distinction between what is desired and what is desirable? When we value anything we are not simply desiring it but regarding it as desirable. We judge that, from some point of view, it is worthy to be desired. Now it may be said that in all desire there is an implicit judgment of this kind; but it is important at least to remember that the judgment does not always become explicit. The fact that the distinction here involved-like most psychological distinctions-is not one that can be rigidly drawn; that we can hardly desire an object without in some degree judging it to be worthy of desire, and that, on the other hand, our judgments of value are often little more than expressions of the fact that we desire certain objects; this fact, so far from rendering it unimportant to draw the distinction, only emphrsizes the necessity of bearing it in mind. Distinctions which break down are generally those that it is most important to draw. In the present case, as it seems to me, the real distinction is not between desire and value but rather between the lower and the higher forms of desire itself. The less developed manifestations of desire, those that approximate most nearly to simple animal appetite, may, without much unfairness, be regarded as merely subjective phenomena. There is practically no objective judgment with regard to the worth of the thing desired. What we have is simply the subjective fact of an agreeable or disagreeable feeling accompanying the presentation of particular objects, together with an impulse directed towards the attainment, removal, or retention of the objects involved. Such desires are very much on the same

1 Op. cit., p. 16.

2 Hhrenfels does not appear to be acquainted with the riews of Sidgwick on this subject. At least, in his historical sketch of the treatment of it at the end of his article Ueber Fiihlen und Wollen (pp. 618-634), he makes no reference to Sidgwick J. S. Mill is also very inadequately dealt with in that sketch, and is, rather curiously, placed after Bain. That there is no reference to Green or Ward is perhaps less surprising. 
psychological level as instinctive movements ${ }^{1}$; and just as the latter imply no definite judgment as to the adaptation of means to end, so the former imply no definite judgment of worth. But in the more fully developed forms of desire this is no longer true. The consciousness of the end involved becomes more and more pronounced; and what was at first a mere preference based on feeling becomes in the end a conscious choice based on a judgment of value. Now the real question here, as in so many other cases, is whether the more developed is to be interpreted in terms of the less developed, or vice versâ. Ehrenfels's statements suggest the former view, though the modifications subsequently introduced leave it somewhat doubtful whether this was his real intention. On the whole he appears to mean that our irrational feelings and impulses have a priority over our rationally determined ends, and that the worth which we attribute to the latter must in the long run be explained by the presence of the former. Now this view seems to me to be a relic of Hume's doctrine of the subordination of reason to passion". It is no doubt true that our natural impulses present themselves at first as instinctive tendencies, without any appearance of a determination by rational principles; and, when reason does appear, it seems at first as if its practical functions were limited to the calculation of the best means for the realisation of the given ends. It seems as if reason were unable to create any fresh motive, as if it were entirely destitute of propulsive force. "Reason the card, but passion is the gale." But further reflection ought, I think, to convince us that this is not strictly true. Its illusory appearance of truth is due to our tendency to think of each of our desires and impulses as an independent force; instead of recognising that they are elements in a more or less systematic whole, and take their character from the totality within which they stand. Though we say sometimes that a man has "the

1 I.e. they depend rather on simple association than on judgment.

In his article Ueber Fühlen und Wollen (pp. 534 sqq.) Ehrenfels elaborates what is essentially Hume's view on this point in a highly interesting way. I think, however, that he somewhat confuses the issue by making it turn on the question whether reason can influence the will without the mediation of feeling. Even Kant, to whom Ehrenfels is here explicitly referring (as also later, pp. 624-625), did not really mean to deny that reason influenees us through the nediation of feeling, but only to affirm (1) that the objective side in this influence has priority over the subjective, and (2) that the kind of feeling involved in this mediation is different in kind from the simple pleasure or pain accompanying the gratification of our natural appetitus. He scems to admit, however, that it is a kind of pleisure reached through pain. Cf. Caird's Critical Philosophy of Kant, Vol. II. pp. 276-277. 
obstinacy of a pig," we probably do not quite mean what we say. In reality the pride of a peacock or the anger of a bear is a very different moving force from the passion to which we give a corresponding name in man; and in different men such passions are widely different, in accordance with the character or point of view, i.e. in accordance with the universe in which they are placed, or the appercipient system by which they are brought to unity. If that system or universe be a rational system, its rational character will make itself felt, so to speak, down to the very finger-tips of the organic unity which it dominates. Reason, it may be said, only disposes the content. But the disposal of the content is everything. The content so disposed is quite truly constituted by the reason which disposes it; it is made into something which it would not otherwise be. Reason, then, I would urge, at least transforms the desires which enter into the life of a rational being. But it does more even than this. It produces new ones. It creates for us all those desires that depend on a view of life as a systematic whole, and, similarly, of all those that depend on a view of the world as a systematic whole. Now these form a considerable element in the human consciousness. Ehrenfels refers (p. 88) to the Stoics as an instance illustrating the incompetence of reason to create any fresh impulse in life. But what the Stoics and other thinkers of that period illustrate is rather the vanity of throwing aside the concrete content of life and sinking back upon the abstract unity of the individual consciousness. So far as the power of reason is concerned, it might very well be urged that the Stoics did after all succeed in some degree in creating for themselves a fresh interest in life by means of the conception of a life according to reason; and that in this way they may be taken as illustrating rather the power than the impotence of thought. But they illustrate it in a one-sided way, inasmuch as they had not sufficient confidence in the ability of reason to master the objective content of experience, and so rejected the particular desires instead of systematising them.

This leads us to another point. Such considerations as I have now adduced ought, I believe, if fully thought out and appreciated, to convince us that in our practical life reason is not to be regarded as an otiose addition to a collection of particular impulses existing independently of it. But further reflection may lead us to go beyond even this. Instead of regarding the ends which reason determines as being entirely constituted by particular impulses which are independent of reason, we may be led to think that even our particular impulses, as they appear prior to the development of reason, are not without reference to that development. It is, indeed, now 
pretty generally recognisid that our pains and pleasures are not accidental phenomena, any more than our instinctive movements; but that they are all more or less definitely determined by biological ends, i.e. by ends which are not consciously present to us until they are determined for us by rational reflection. But if this is so, it seems to imply that the ends determined by reason are in a sense prior to our particular desires, rather than vice versâ. And indeed this is in effect what Meinong urges in his criticism of Ehrenfels (op. cit. p. 15), though I have no reason to suppose that the former writer, any more than the latter, would be prepared to accept the general position that I am here endeavouring to indicate. What I mean to imply is that our particular desires and impulses, like our particular instinctive movements, contain in themselves a kind of natural prolepsis, a kind of anticipation of ends which are not yet consciously present. How this anticipation is possible is not a question that can be here discussed. It is a question that must present itself, in many different forms, to all who are concerned with the genetic treatment of psychological processes. Perhaps it may still be true for us, as it was for Kant, that the "blind" working of the faculties of imagination and of other mental activities that are on the imaginative level, is one of those mysteries of the mental life that have never yet been sufficiently explored; but if there is any truth in the view that such an anticipation is to be recognised, then there is a sense in which value is prior to and explanatory of desire. Even in ordinary life we tend to regard as "unnatural " those instincts and impulses which cannot be justified as having any value for reason; and though the fact that there are such "unnatural" tendencies may be held to shew that the growth of our impulses is not entirely dominated by rational principles, yet the fact that they are regarded as abnormal seems to indicate that on the whole even our prerationalexistence is guided by a reference to those principles of value which reason subsequently discovers. It appears, then, that there is some ground for believing that the idea of value is in reality more fundamental than desire, or, in other words, that the objective side (the reference to an end) in the fully developed phenomenon of desire has a certain priority over the subjective side (the pure element of feeling which accompanies the reference to an end, whether or not the latter be consciously present) 2 .

1 For some further remarks on the way in which the proleptical reference in desire is to be understood, as well as on some other points bearing on this subject, I may perhaps venture to refer here to the Note on Value in my Introduction to Social Philosophy (2nd Edition, pp. 266-271). 
With reference, next, to the relation between desire and feeling, the view of Ehrenfels is thus summarised". "If in any particular case we are placed before the possibility of desiring either the end $a, b$, or $c$, \&c., or of desiring nothing at all, then that psychical state always realises itself which brings with it the relatively most favourable condition of feeling (i.e. relatively most pleasure and least pain) for the nearest distinguishable portion of time adjoining. The most unselfish acts of desire are subject to this law. Even one who knowingly offers up his life for another, is happier at the moment when the requisite act of will takes place, or at least less unhappy, than he would have been if he had neglected the performance, i.e. if the requisite act of will had not realised itself in him. The desiring or not desiring of anything always realises the greatest possible state of happiness for the immediately succeeding time, just as water in a vessel that is shaken always finds the lowest positions; but, just as in the case of the water, so in the case of the desire, the result is brought about without any consciousness of the end. The greatest possible pleasure of the immediately succeeding moment sets itself forward of its own accord, through the simple force of our psychical mechanism, as a consequence of the universal law of the greater power which presentations that have a relative tendency to promote happiness possess of preserving themselves; and this happens even when we are not explicitly desiring happiness. Such cases are psychologically considerably the larger number. Not only in the case of those acts of desire which are ethically on a high level, but even in the case of the most commonplace so-called egoistic impulses, such as in the case of the appetite for food and drink, the aim of securing a future condition of feeling is entirely absent. Accordingly we are able to take as our ultimate end not only the promotion of our own happiness but also any other conceivable object, provided that we find in the anticipation of that object a more favourable condition as regards happiness than we should be able to realise without that anticipation."

Ehrenfels remarks (p. 92) that this view has "never yet been controverted." Perhaps we may safely add that it is never likely to be. At any rate, the only criticism that I

1 The view of Ehrenfels on this point is more fully given in his dissertation "Ueber Fühlen und Wollen" The sbove statements are his own summary of the general results of this dissertation. The latter is well worth reading for its own sake. I am not sure that it is not even more important than the articles on Value. It is to be found in the Sitzungsberichte der kaiserl. Academie der Wissenschaften for 1887 (Wien). It is certainly one of the most thorough discussions of the relation between feeling and desire with which I am acquainted. 
should care to make upon it is not one designed to throw doubt upon its truth, but rather upon its importance. I hardly see how any one can dispute that what we desire at any moment is that which at that moment presents itself as the most satisfactory complement of our present condition. Indeed, I can hardly tell what is meant by desiring an object except regarding it as supplying a defect in our present consciousness; and I do not see how we can think of the supplying of such a defect without a feeling of gratification in the thought of it. On this point it seems to me that J. S. Mill was perfectly right. To desire a thing and to think of it as pleasant, in the sense indicated by Ehrenfels, are but two aspects of a single psychological fact ${ }^{1}$. So far, therefore, from seeking to controvert his position, I would only suggest a doubt whether it is not tautological. Even a tautology, however, may sometimes serve to emphasize an important truth; and if Ehrenfels's statement were simply intended to bring out the two sides that are always present in desire-what may be called the subjective and the objective side-I should have no objection to it, but should regard it as a useful contribution towards the precise formulation of the relationship between the two sides. But unfortunately Ehrenfels sets forth his view as the statement of a "law," and seems to regard it, not as a tautology ${ }^{2}$, but as throwing light on

1 Of course I am very far from meaning to imply that Ehrenfels has not put the matter in a vastly more satisfactory form than any in which it was ever stated by Mill. I doubt whether it could be put much better than it has been by Ehrenfels, except that the idea of the "next succeeding moment" does not seem to me a very happy one.

8 The reason why it does not present itself to Ehrenfels as tautological is that he draws a sharp distinction between feeling and desire. He does not simply regard them as two distinguishable aspects in the totality of our mental life, but rather as two entirely different elements. Hence he is led to look for a law of their connexion. He explains (Ueber Fithlen und Wollen, p. 561, etc.) that feeling may exist without desire, and desire without feeling. They are not necessarily implied in one another. There is of course some plausibility in such a view, and it cannot be denied that several of Ehrenfels's illustrations are very striking. But I think the plausibility of it arises largely from a failure to hold firmly to the view that feeling means nothing but agreesble or disagreesble consciousness. If we are careful, for instance, not to confound simple disagreasbleness with the organic sensation of pain, and at the same time not to confound either feeling or desire with emotion, and not to confound desire with mere animal appetite or impulse, then I think we shall be able to recognise that there is always an element of feeling in desire, and that that element is the inevitable counterpart of the objective side of desire, and not something requiring to be connected with desire by means of a law. The absence of any sufficient account of emotion seems to me to be one of the weakest points in Ehrenfels's psychology (as also, I think, in Brentano's). Emotion tends to be confounded with feeling on the one hand and with desire on the other, and this is a fruitful source of confusion. 
the machinery by which desire is movtd. So regarded, I cannot but think that it is most misleadin ${ }_{r}^{r}$. Here again, in fact, we are brought back to the question whether the complex phenomenon of desire is to be accounted for wy directing attention exclusively upon its subjective aspect; and again I must emphasize my conviction that it is not. The work of Butler and Hutcheson seems to me, on the whole, to have settled this point. Desire is not to be regarded as primarily directed, even unconsciously, towards the pleasure of its own satisfaction; but on the contrary the fact that we get pleasure in this or that particular way is due to the fact that we have wants directed in this or that direction-wants which "terminate in their objects." How it comes that we have wants directed in this or that direction is then a further question; and I would urge that the answer to this question is to be looked for rather from biology than from hedonistic psychology-if, indeed, in the long run, it can be found anywhere short of metaphysics.

Another interesting question is raised by Ehrenfels in discussing the possibility of error in attaching value to objects. It seems clear that there can be no error where there is nothing of the nature of judgment; and accordingly the question how far judgment is involved in the valuing of objects arises at this point. Here the distinction between Eigenwerthe and Wir. kungswerthe does him yeoman's service. It is evident that in the case of Wirkungswerthe there is at least an implicit judgment involved - the judgment, namely, that some given object is a means to a desired ${ }^{1}$ end. This judgment may be erroneous; and accordingly all instrumental values are hypothetical. It is otherwise in the case of Eigenwerthe, i.e. in the case of objects that are valued directly for their own sake. In such cases we do not first apprehend an object and then ascribe value to it as a predicate. The value is rather directly given along with the apprehension of the object to which it is ascribed. Hence in such cases there is not, at least in the first instance, any judgment invoived at all, but rather a simple feeling (p. 94). "Here, therefore, one cannot consistently speak of an estimate of value [Werthschätzung] (in the sense of a weighing of the value of an object), still less of a judgment of value [Werthurtheil], but only of counting valuable [Werthhaltung] or simply valuing [Werthung]." In such cases, therefore, there is also no possibility of error, since there is no judgment formed. In the case of a true Eigenwerth Ehrenfels agrees with $\mathrm{Fe}$ rishtah :- "Apprehended as a prize, a prize it is." Now in this view I suspect there is an error due to the adoption of the

1 Or desirable. 
attributive theory of judgment. If we suppose the essence of judgment to consist in the attribution of a predicate to a subject previously given, then it is no doubt true that in the direct valuing of an object for its own sake there is no such predication implied. As Mr Bradley would say, the "that" and the "what" are not, in such a case, set over against one another. But if we recognise, as I think we must, that the essence of judgment consists rather in the creation of a world for ourselves by the placing of particular contents within an ideal system, then every case of the valuing of any particular object is, in this sense, a judgment. But, even without entering into a discrission of the question whether the judgment necessarily involves an opposition between the "that" and the "what," I think we may see that there must be some error in the position taken up by Ehrenfels. It is no doubt true that in the case of objects that are directly apprehended as valuable, there is an immediate feeling of satisfaction in the presentation of the object. But is this feeling the same thing as the valuing of the object? Ehrenfels seems (p. 94) to say that it is; and it is on this view that his doctrine turns. Now, far be it from me to deny that all feeling of pleasure may be fairly described as a sense of value. But it is so, as I have urged, only in an anticipatory or proleptical way. It seems an abuse of language to say that in the strict sense, we value anything without reflecting upon it and comparing it with a standard. A man may feel pleasure in many objects which he does not value in the least. It may be said that pleasure is for the merely sentient consciousness what the appreciation of value is for the reflective consciousness; but this is only to say that the feeling of pleasure is an anticipation of the judgment of worth. In short, whether or not we are to maintain that the consciousness of value involves a judgment in the ordinary logical sense (a question to which the answer may depend a good deal on our view of the essential characteristics of the logical judgment), it can hardly be denied at least that the consciousness of value involves judgment in the sense of judgment upon. It is one of the normative facts in our psychical life. It involves comparison with a standard, and this surely implies judgment. Here, in fact, as at previous points, it seems to me that Ehrenfels is emphasizing the subjective element in desire at the expense of the objective. Desire involves feeling, but it also involves the apprehension of an object: value involves feeling, but it also involves reflection upon a standard of comparison or upon the idea of an end.

The only other point of much importance dealt with in this first article of Ehrenfels's series is the idea of negative value, with 
which it is impossible' to-deal here. I regret that the number of interesting points contained in the first article has prevented me from dealing also in a similar way with the points contained in the other four. I believe, however, that most of the points contained in the other articles are of a less controversial character. Their interest seems to me to be mainly psychological. They throw light on the movements of the human mind in its estimation of the value of various kinds of objects rather than on the fundamental idea of value itself. It is natural that Ehrenfels, with that strongly subjective tendency on which I have already commented, should be chiefly attracted by this side of the subject ${ }^{3}$. I have perhaps already sufficiently indicated how unsatisfactory $I$ believe this manner of treatment to be. But this feeling of dissatisfaction does not at all prevent me from appreciating the high Wirkungswerth and even Eigenwerth of much of what Ehrenfels has written. His treatise seems to me to be a singularly original, subtle, and carefully worked out contribution to an important subject.

The views of Meinong, as I have already indicated, are to be found in his interesting treatise entitled "Psychologisch-ethische Untersuchungen zur Werththeorie." This is on the whole a more elaborate work than that of Ehrenfels, aiming more distinctly at systematic completeness, and in several important respects it appears to me to carry the discussion of the subject a stage deeper than Ehrenfels has been able to go. The general outlines of Meinong's mode of treatment have been already indicated in the short notice of his book which has appeared in Mind $^{2}$. The points discussed in it are much too numerous and intricate to be dealt with in any detail in such an article as this. Perhaps also the fact that it has appeared in the form of a book, and not, like the discussions of Ehrenfels, merely as a series of articles in a Journal, makes it more accessible to those concerned, and so renders it less needful to give an account of his position. At any rate, all that I can do here is to notice one or two of the leading points which seem to me specially interesting

1 I may note here that a similarly subjective vein seems to me to be characteristic of much of the work of the Austrian school of economists. With all their references to what they call "objective value" they seldom appear to get beyond the consideration of subjective appreciations. In this respect the strongly objective treatment of such a writer as Wagner seems to me to have a marked superiority. I believe that in the more general treatment of value also, as distinguished from the purely economic treatment, an objective point of view is of great importance.

2 For April, 1895. The short account there given is, however, somewhat misleading, inasmuch as it may be interpreted as iniplying a closer relationship betwcen Brentano, Meinong, Ehrenfels, and the Austrian economists than is actually to be found. 
and important. A few other points have already been incidentally touched upon in dealing with the views of Ehrenfels.

There can be no doubt that one of the most interesting and fundamental points in the work of Meinong is his discussion of the nature of the judgment involved in the estimate of value. This seems to be the point to which Meinong himself attaches the greatest importance, and it is perhaps also the point at which his divergence from the views of Ehrenfels is most marked. Meinong fully recognises that in all appreciation of value an element of judgment is involved; but he combines this recognition with the doctrine that the appreciation itself is of the nature of feeling rather than of judgment. He is thus led to maintain the existence of a peculiar class of feelings which he terms Urtheilsgefuihle, of which the appreciation of value is one. These judicial feelings (if we may use such an expression) are to be distinguished from presentational feelings (Vorstellungsgefühle), and possibly also from appetitive feelings (Begehrensgefühle) and some others. The point which Meinong wishes to emphasize by these distinctions is, I think, a sound and valuable one, viz. that feeling is not an isolated element in our mental life, existing independently of the content with which it is connected, but rather that it has its character determined, at every stage in its development, by the nature of its content. "A feeling without content," as he says (p. 34), " is not less absurd than a presentation without content." This seems to me perfectly correct. There is too great a tendency among modern psychologists to represent feeling as a thing apart-a sort of Ding an sich ${ }^{2}$, and to make it appear as if it made no difference to the nature of the feeling whether it appeared at the sensational, at the perceptional, or at the conceptional level in our mental development. I believe there could be no more fatal error. The element of feeling seems, more than any other element in our inner experience, to have a direct reference to the unity of our conscious life; and, if this is so, it can hardly fail to take its tone and colour from the nature of that unity. The feeling which accompanies that elementary undifferentiated unity which is commonly known as coenaesthesis can hardly be the same kind of feeling as that which accompanies the definite presentation of an object; and the latter again must surely be widely different from the feeling that arises in connexion with the unity of self-consciousness, by which objects are not merely apprehended but thought. That in every case the feeling of pleasure is a certain sense of the harmony of the content with the form of unity to which it is

1 Somo recent psychologists have actually described it in this way. 
brought, and that the feeling of pain is a corresponding sense of disharmony, may readily enough be granted. But to suppose that the sense of harmony which accompanies the mere flawless continuity of the "this-mine" feels to us the same as would the harmony, say, of a beatific vision, appears to me to be little short of an absurdity. What feeling is for us seems clearly to depend on the nature of the content within which it emerges. So far, then, I find myself entirely in agreement with Meinong; if I have rightly grasped his meaning. When, however, he goes on to suggest that, besides recognising a distinction between the feeling which accompanies presentation and that which accompanies judgment, we ought also to recognise a distinct kind of feeling which accompanies (or, as he is even willing to say, which is caused by) desire, I cannot but suspect that he is on the wrong track. He is misled, I imagine, by the fact that he has approached the study of psychology rather according to the analyiical than according to the genetical method. He is thus led to look for a fucling correspunding to every recognisable element in the analysis of our psychical life. I believe it would be more fruitful to approach the matter from the point of view of mental evolution, and to look for a different kind of feeling corresponding to cvery stage in the process of development. Thus, if we recognise that there are three broadly distinguishable stages in our mental development-(1) the stage of undifferentiated sensation, (2) that of the definite presentation of objects, with its ideational accompaniment of memories and images, and (3) that of conceptions and ideals-, then we should naturally expect to find three levels of feeling corresponding to these, which some writers have endeavoured to distinguish by using such terms as pleasure, happiness, and bliss. And if we recognise more stages in the development of our inental life, we should similarly expect to find more stages in the growth of feeling. At each of these levels, again, we might perhaps be able to distinguish receptive and active elements in our consciousness, as well as the element of feeling; and these elements would also present themselves in different forms according to the level at which they appear-the active side for instance developing from the vague promptings of undefined impulses, through definite animal appetites, to the stage of fully-formed desires. Approaching the matter in this way, we should not naturally look for a particular kind of feeling accompanying desire, but only for a particular kind of feeling accompanying the stage at which desire emerges. This point, however, is perhaps not of much importance with reference to Meinong's main contention; and we need not now press it further.

Having thus endeavoured to establish the existence of a 
class of Urtheilsgefuhle ${ }^{1}$, Meinong next goes on to subdivide this class into Wissensgefuihle (feelings of knowledge) and Werthgefuhle (feelings of value). Here I must confess that I cannot so easily follow him. The distinction which he wishes to draw, if I understand him rightly, is that between the appreciation of a subjective state and the appreciation of the object to which a subjective state is directed, or which forms its content. We may appreciate the simple fact of knowing, apart from the consideration of any value that may be attached to the object known. The desire for knowledge is in part simple curiosity, the mere desire to know for the sake of knowing. Such simple appreciation of knowledge as such is what Meinong appears to mean by Wissensgefuihl. A Werthgefuihl on the other hand is the appreciation of an object judged to be valuable. In the latter case we have a definite judgment of value: in the former case we have only, as it were, a valuing of judgment. I would urge, however, that we have a valuing; and consequently that it is in reality a species of Werthgefuihl. The difference to which Meinong appears to be here calling attention is that in one case there is an explicit judgment of worth pronounced upon an object, while in the other case there is no such explicit judgment, but only a feeling of appreciation, similar to the feeling which accompanies a simple presentation (Vorstellungsgefihl). But is it otherwise with the majority of Eigenwerthe? The direct appreciation of the beautiful, for example, does not seem to involve any explicit judgment of worth. It is an Urtheilsgefiihl only in the sense that it is a feeling of appreciation which belongs to the intellectual level, and which can readily be expanded into a definite judgment. But when we appreciate knowledge as such, is not this also on the intellectual level, and could not this also be expanded into a judgment of value? No doubt, as Meinong urges, the desire of knowledge may be distinguished from the desire of truth. The lover of truth is devoted to an object to which he attaches value, just as is the lover of beauty or goodness or any other valued end. The lover of knowledge as such, on the other hand, i.e., as Meinong puts it, of mere subjective truth, is merely appreciating an intellectual process, without reference to the value of its content. But still he surely is valuing that process. He is, more or less explicitly, saying to himself that it is worth while to know. Apart from this, I am bound to confess that I am somewhat sceptical as to the existence of such an apprecia-

1 Meinong's insistence on the distinction between Vorstellung and Urtheil may probably be taken as one of the evidences of his conneriun with Franz Brentano. Cf. the latter's Psychologie vom empirischen Standpunkte, Vol. I. pp. 266 sqq. 
tion of knowledge in the abstract, knowledge apart from all reference to the truth and importance of its content, as that to which Meinong here seems to refer. The human mind is often apt to be very abstract in its point of view. It leaves out many relevant circumstances, and it is hardly aware that it is leaving them out. And no doubt in the pursuit of knowledge such an abstraction is frequently to be found. We fancy that we simply want to know, and that we care nothing for the importance of the particular content which we are pursuing. A man may even come to care for his own opinions simply because he holds them, until he almost loses sight of the question as to their truth or falsehood. But this is only possible as a kind of side-eddy in the stream of our conscious life; and the fact that it is possible at all seems to be due to that complication of our mental structure, which enables us to pass rapidly from one point of view to another. When we appreciate an opinion that we know to be false, or that we suspect to be false, we at least "make believe" that it is true at the moment at which we appreciate it. We place ourselves, for the moment, at the point of view from which it seems to be a truth; and it is sub specie veritatis that we appreciate it. I cannot think, therefore, that, in such a case as this, an implicit judgment of value is entirely absent. However, as Meinong himself seems in the end inclined to withdraw his own distinction, it is perhaps not worth while to deal with it farther. It seems clear at least that it is not a distinction of any great importance. The only reason why I have thought it necessary to direct attention to it at all is that the drawing of this distinction appears to me to bring out a certain defect in Meinong's point of view. He is too prone, I think, to draw minute distinctions, and to "cut things asunder with an axe." He is anxious, for instance, to fasten down the feeling of value to one definite place in our mental life. Such an effort is no doubt praiseworthy; but I suspect that it leads him to some extent to forget the continuity of consciousness. In this particular respect I am disposed to prefer the treatment of Ehrenfels, for whom all feeling is a feeling of value. In a developing organic system the distinctions that have to be drawn can seldom be absolute distinctions. They are rather, as a rule, distinctions between the more and the less explicit. That kind of appreciation of an object which we call valuing it occurs, in a fully developed form, only at the conceptional level in our intellectual life. It is the accompaniment of a process of judgment and of a definite conception of an end. But we ought, I think, to recognise, at the same time, that this kind of appreciation is only the fully developed form of an element which appears at the very lowest stages in our conscious life, 
and which at every period in its history grows with its growth and strengthens with its strength. This is a point which the subtle distinctions of Meinong appear to me to a large extent calculated to obscure.

In connexion with this point, Meinong is naturally led to give a good deal of attention to the psychological nature of the process of judgment. Here again the influence of Brentano seems unmistakable (Psychologie, Book II., chap. vii.) ${ }^{\mathfrak{1}}$, and I think it is on the whole a good influence. He is led by it to treat the judgment as being essentially rather existential than predicative, i.e. as having its fundamental characteristic, not in the attribution of a predicate to a subject, but rather in the attribution of a content to reality. I believe that the working out of this view would throw much light on the nature of the judgment involved in valuing, especially if it were recognised that the reality to which attribution is made must be regarded as an ideal system. The significance of the valuing of an object as consisting in the recognition of the harmony or - want of harmony of the object with the ideal system within which it is placed, would thus be made apparent. Meinong, however, does little more than touch on this aspect of the subject, promising a fuller discussion of it in a future treatise. Meanwhile, the distinction which he draws between a "Haupturtheil" and a "Nebenurtheil," and the way in which he connects the idea of value with the former, seem to point in the right direction. I can only hope that, in his further elaboration of this point, he will fully recognise that the essential characteristic of a Haupturtheil lies in its placing of a particular content within an ideal whole.

Another important question which is discussed by Meinong, is that with respect to the relationship between the subjective appreciation of value and the objective fact of value itself, i.e. the relationship, as he expresses it, between Werthhaltung and Werth. He is careful to explain that these two things are by no means identical (especially p. 24); and by his insistence on this point he has, I think, corrected the almost pure subjectivism both of Ehrenfels and of the Austrian school of economists".

1 I cannot find any similar evidence of the influence of Brentano on Ehrenfels with regard to this point. Indeed, as I have already indicated, a failure to give sufficient attention to the nature of judgment seems to me to lie at the root of much that is defective in Ehrenfels's general treatment of the subject.

2 With these economists "objective" is almost a term of reprasch. Intrinsic value they seem always to treat as purely subjective. As regards Ehrenfels, his subjectivism is partly corrected by himself, when he adds, as above noticed, "possible" desires to actural ones But it was reserved for Meinong to bring out the true significance of this (p. 25, Note).

$\mathbf{M .}$ 
At the same time the subjective side is still for Meinong the more important; and he even concludes this part of the discussion (p. 30) by leaving it problematical whether there is, strictly speaking, anything that can truly be described as objective value. Purely objective value, he insists, would be the same as absolute value; whereas the only value with which we can ever deal, at least from the psychological point of view, is necessarily relative (referring to a particular object on the one hand and a particular subject on the other). In short, while Meinong emphasizes the fact that to have value is not the same thing as to be valued, he is yet equally emphatic in maintaining (p. 29) that to have value must always involve the possibility of being valued by some assignable consciousness; and we are thus precluded from recognising, so long at least as we confine ourselves within the region of ordinary experience (as we do in Psychology), the existence of any strictly objective or absolute value. No doubt this is true. But is any one interested in maintaining the existence of objective value, in the sense of a value which is not a value for some sort of consciousness? I suspect that at this point Meinong betrays the limitations of a thinker who has won his spurs in the field of English empiricism $^{2}$, and who has never adequately appreciated the work of the great German idealists. If objective existence means existence for "Bewusstsein überhaupt," or existence for an ideal self, then no doubt it will still be true that such existence does not fall within the domain of the empirical psychologist ; but it will naturally be asked why any one writing on such a subject as value should arbitrarily restrict himself to such an empirical point of view. It is surely obvious that, if he is to do justice. to his subject, he must at least advance to the "erkenntnisstheoretisch" point of view, if not to a point of view that is distinctly metaphysical. How his treatment of the subject is weakened by his failure to adopt such a standpoint will, I believe, shortly become apparent. In the meantime, it is something, at any rate, to have advanced from the mere subjectivity of individual feeling to the quasi-objectivity of a possible consciousness, even if the objectivity thus reached should be little better than (as with Simmel ${ }^{2}$ ) a sum of subjectivities.

The interest of the remaining part of Meinong's work is to be found chiefly in the way in which he develops the relationships of various kinds of value to different subjects of reference. All value is value for some subject, actual or possible; but the

1 His excellent Hume-Studien are the only provious writings of his with which I am acquainted.

2 Einleitung in die Moralwisenechaft, Vol. II. p. 8. 
value of objects, especially in the region of morals, is often complicated by the fact that an individual refers them not merely to his own point of view, but also to that of some one else. We sometimes value objects altruistically; and occasionally also we value objects because we know them to be injurious to some one else. Meinong deals with such cases by introducing a mathematical mode of treatment. He symbolises the point of view of a given individual by the letter $E$ (Ego) and that of some one else by the letter $\boldsymbol{A}$ (Alter). Similarly, he introduces various symbols to stand for positive and negative values, \&c. He is thus able to formulate a number of equations expressing different modes of relationship. How far this method of treating the subject is helpful, I hardly feel myself able to determine. I suspect that it often leads to results that are more ingenious than useful. In some of these parts of Meinong's work, as in much of the work of the Austrian economists, I think there are sometimes to be found traces of the supersubtlety of workmen who are "striving to do better than well," and who often obscure their fundamental principles by over-elaboration of detail. But this judgment has perhaps only a subjective significance.

There is one point, however, in the working out of Meinong's doctrine which seems to me to have great importance, and to throw a flood of light upon the deficiency of his point of view. In dealing with ethical and especially moral'. values, he is led (especially pp. $171 s q q$.) to discuss the question from what point of view we pass judgment on the dispositions of men's characters. From the moral point of view such dispositions are to be regarded as Wirkungswerthe. They are valued for their consequences upon the social environment ("die umgebende Gesammtheit"). But what is the subject to which such values are referred? Meinong decides that the subject is neither $E$ (the individual judging) nor $A, B, C$, \&c. (other individuals concerned), but rather what may be symbolised by $X$ (a hypothetical "impartial spectator," as Adam Smith would have said). The working out of this idea is one of the most interresting and subtle parts of Meinong's book. He deals, in particular, with the difficulties that seem to arise in connexion with it. The first is (p. 176) that, if an impartial spectator is to be judge, it would appear as if egoistic dispositions ought to be more highly valued than altruistic; since it is on the whole of more importance (from the point of view of "die umgebende

1 Meinong uses the term "ethical" in a wider sense than " moral," the former (if I understand him rightly) relating to conduct in general, the latter to conduct regarded as good or evil The asthetic appreciation of conduct, for instance, would be an ethical, though not a moral, fact. 
Gesammtheit") that individuals should attend to their own interests than to those of others. But the opposite principle seems to be adopted in our actual moral judgments. Meinong gets over this difficulty by means of the idea of marginal utility. Egoistic dispositions are little valued because they are so plentiful ; they are like air or water. The other difficulty has reference to the degree of value attached to cases in which a man's own good is sacrificed for the sake of others. We tend on the whole to appreciate such sacrifice the more in proportion to its amount, and also to some extent in proportion to the smallness of the good which it is designed to secure for another. This is the reverse of what would naturally be expected from an impartial point of view. The less the sacrifice and the greater the good secured, the better would the action appear to be. In dealing with this difficulty Meinong introduces a good deal of elaborate symbolic treatment; but the essential point seems to be simple enough. A disposition which leads to the sacrifice of a great egoistic good for the sake of a small altruistic one is a more powerful disposition than one that leads merely to a small sacrifice for a great advantage; and, in fact, the former may be said to include the latter. Hence the former is naturally the more highly valued, though its result in a particular case may seem less desirable. Now I do not deny that there is an element of truth in these explanations. I have no doubt that altruistic dispositions have their value somewhat enhanced by their rarity; and I have no doubt also that we are often inclined to regard with favour an excessive amount of self-sacrifice for a very small benefit because we know that the disposition which leads to such sacrifice will also lead to other sacrifices for more worthy objects, in which the game will really be worth the candle. But I think Meinong has overlooked some important points.

In the first place, I think he is open to an objection somewhat similar to one which, in a different connexion, he himself has urged against Ehrenfels (p. 25, note), viz. that his treatment of this whole matter is simply an artificial way of getting beyond an inadequate point of view. The hypothetical subject symbolised by $X$ is dropped upon us, as it were, from the clouds. I find no adequate explanation of the reason for adopting the point of view which is thus symbolised, or even of the possibility of adopting it. Such a universal and (in the truest sense) objective standpoint seems wholly foreign to the individualistic psychology into which it is thus suddenly introduced. If the treatment throughout had been metaphysical or "erkenntnisstheoretisch," such an ideal subject would have fallen into its proper place at once; but, as it is, it seems 
to be sprung upon us unawares, just as in Ehrenfels's sudden addition of "possible" desires. Such a mode of treatment would be objectionable even if in the end is led to satisfactory results. But I think it brings, besides, some mischievous consequences in its train. On these, however, I can only briefly touch.

The sudden way in which the idea of this hypothetical subject is introduced seems to prevent Meinong from recognising that it is essentially of the nature of an ideal self. The important consideration is not merely that $I$ am capable of referring the valuation of particular objects to an indifferent or universal point of view, but also that I am capable of identifying myself with such a standpoint. It is not merely that things may be valued from the position $X$, but that the individual $E$ does actually (under certain conditions) value them as if from that position. This is the point that requires explanation; and the only adequate explanation of it seems to be found in the consideration that the individual consciousness has naturally a universal element in it. Now the recognition of this would lead to still further consequences. It would lead us, for one thing, to see that the position symbolized by $E$ is not a simple one. An individual is not merely capable of taking up the indifferent or strictly universal position $X$, but, also an indefinite number of other positions. This fact, which, in another connexion, I have ventured to express by means of the conception of different "universes" within which an individual may live, seems to me to be of the utmost importance ${ }^{1}$; and I suspect that the neglect of it vitiates a good deal of Meinong's quasimathematical treatment, in which $E$ appears to be taken as representing a uniform point of view. But this is not all. If Meinong had recognised that the point of view denoted by $X$ is in reality simply one of the points of view included under $E-$ i.e. that it is essentially the point of view of an ideal self-he might have been led to recognise, further, (what, from his own standpoint, it was scarcely possible for him to do) that an "Eigenwerth," as well as a "Wirkungswerth," may be appreciated from the position $X$. And this might have suggested a more satisfactory solution of the difficulties which he raises than he

1 The idea of the different Apperceptive Systems within which an individual may live is of course due mainly to Herbart. In English it is enough to refer to Mr Stout's masterly article on "Apperception and the Movement of Attention" in Mlind, Old Series, Vol. zvi. No. 1. The idea has the greatest valuc, quite apart from the peculiarities of Herbart's system; and I believe that an adequate recognition of its importance would have added immeasurably to the clearness of the work both of Ehrenfels and of Mleinong. 
has actually been able to find. For surely a large part of our appreciation of altruistic and self-sacrificing dispositions is not due to any thought of their rarity or any calculation of their normal consequences, but is rather a direct and almost æsthetic satisfaction in the attitude of mind which they imply. The power of taking a universal point of view, of rising above the consideration of our own individual welfare, and taking a genuine interest in the welfare of others, seems clearly to be a faculty which possesses more than a mere "Wirkungswerth." It is good for its own sake, and is so appreciated (as Shaftesbury might have put it) by the truly cultivated moral connoisseur, even "in the scorn of consequence." It is, on the whole, only as a stimulus to a jaded moral sense, that a calculation of the "Wirkungswerth" of such a moral disposition is of any ethical importance. What has ultimate moral worth is the simple fact of a man's being such a person. But to understand why this should be so, it is necessary to have a view of the nature of personality, of the ideal involved in it, of the good at which it aims, such as is scarcely attainable by means of empirical psychology, but only by a metaphysical inquiry into the constitution of the self and its place in knowledge, feeling, and action.

These few remarks must now suffice as an indication of what seem to me to be the strong and the weak points in Meinong's work. There is much more in it that is interesting; and there is also, I think, some more that is open to criticism. But the strength of it lies, throughout, in the patient thoroughness with which point after point is raised, and difficulty after difficulty met. I trust I have given a sufficient " taste of his quality" to make his strength in this respect apparent, and to induce many readers to go faithfully through his most suggestive discussion for themselves. I hope I have also succeeded in bringing his weak point to light. It consists in his tendency-natural no doubt in a disciple of Franz Brentano-to approach his subject vom empirischen Standpunkte. This means, on the whole, from the point of view of individualistic psychology ; and if Meinong ever gets beyond that point of view, it is only by a kind of sleight-of-hand. $\mathrm{He}$ undermines it by ingenuity, instead of engulfing it by depth. I can only hope that the future discussions which he promises on the true nature of judgment may carry him beyond this merely psychological standpoint, and that we may soon have the pleasure of welcoming a series of Metaphysisch-ethische Untersuchungen zur Werththeorie from the same accomplished hand.

I have now only room to add three small observations on the general subject under discussion.

1. The importance of a treatment of Ethics from the point 
of view of Value seems to me considerable. If there has been any noticeable advance in the attitude of writers on Ethics in England during the last generation, it has perhaps consisted in the adoption of this point of view, more than in anything else. A tendency in this direction can be seen in nearly every school of thought-in the idealistic school, in the biological school, in the school of rational Hedonism, and even in the intuitionist school, in so far as Dr Martineau's attempt to arrange springs of action in their order of worth may be taken as typical of that school in its most recent stage of development. In the preceding generation, on the other hand, both intuitionists and utilitarians were apt to rest their ethical doctrines almost entirely on psychology. Now it is clear enough, from the example of Ehrenfels and Meinong, that an attempt may be made to treat even Value on such a basis. But on the whole I am convinced that, as soon as the idea of Value is seriously taken as the fundamental problem in Ethics, the attempt to rest Ethics on Psychology will be seen to be futile, and a safer foundation will be sought. The new foundation may be for a time, as with Professor Alexander, a biological or quasi-biological one; but I believe that this must soon, in its turn, give place to a metaphysical one. But this is perhaps too much of the nature of an obiter dictum, and I will not now press it further.

While, however, the idea of Value has the advantage of directing attention to the metaphysical (as distinguished from the purely psychological) implications of ethical theory, it seems to me, at the same time, to have the advantage also of a certain superiority over the old metaphysical idea of "the Good". The latter is too apt to suggest some single end. such as pleasure or perfection, to be attained, once for all, at the end of a process; whereas the idea of Value lends itself more readily to the conception of an organic system of ends, possessing various degrees of worth.

It also serves, better perhaps than any other conception, to emphasize the essentially normative character of ethical science, as being concerned primarily neither with the simple study of existence, nor with the simple inculcation of rules of conduct, but with the investigation of the worth of actions and of types of character'.

2. I cannot but think that it would be an advantage in the treatment of Value if the important distinction drawn by Ehrenfels between "Eigenwerthe "and "Wirkungswerthe" were more carefully observed, and if the former were thoroughly discussed before the latter are touched upon at all. "Eigenwerthe" are

1 Cf. Meinong, y. 85, where, however, the importnnt distinction between a practical and a normative science dues not seem to be recugnised. 
obviously the more fundamental; and it is misleading to mix them up, as both Ehrenfels and Meinong tend to do, with those values which are derivative. One of the advantages of a careful separation between them would be found in the elimination of economic values from the preliminary discussion of the subject. At present there is too great a tendency to regard economic value as the type of value in general; whereas it is only a particular species of "Wirkungswerth"," and not at all typical of the nature of an "Eigenwerth." The idea of marginal utility, for instance, may profitably be extended from the region of economics to that of "Wirkungswerthe" in general; but I doubt whether much significance can be given to it with respect to "Eigenwerthe." It would be well, at any rate, at the outset to get rid of the associations derived from economics, and to start with the treatment of " Eigenwerthe," regarded both from the subjective and from the objective point of view ${ }^{2}$. The signiticance of the various species of "Wirkungswerthe," including economic values, would then become much more clearly apparent; and, in particular, the subordination of all these to intrinsic ethical values would be duly emphasized.

3. My concluding observation is a small one. Some English philosophers object to the use of the term Value as the equivalent of the Herbartian "Werth," and suggest that some such word as Worth would be more appropriate. I suppose it is partly the want of a convenient corresponding verb, and in a less degree of a corresponding adjective (for "worthy" seems to have a connotation which does not quite correspond) that has prevented the latter term from coming into general use. If this difficulty could be got over (say, by using "esteem" and "estimable" as verb and adjective), it might be convenient

1 Economista, as already noted, have sometimes claimed the whole subject of Value as falling within their province. (On this subject I may perhaps refer to some remarks in a paper on the Relation between Ethics and Economics in the International Journal of Ethics, April, 1893.) But it seems clear that even "Wirkungawerthe" are more extensive than the field of economic values. If virtue for its own sake is not an economic good, veither is virtue for the sake of happiness. How the sphere of economic goods ought to be defined is a difficult question. Probably it must, after all, be defined with reference to exchange. I suppose even an "Eigenwerth" would become an economic good if it were susceptible of exchange; but the very fact that anything can be exchanged wuuld, I think, show that it is not, strictly speaking, valued for its own sake. If it can be weighed off agajnst something else, both the objects in question must be regarded as contributing in a certain degree to some common end; and so both are treated as Wirkungawerthe with reference to that end.

- From the latter point of view, it ought, I think, to be recognised that there are degrees of objectivity in Values as in other thingse In fact, it is not so much a question of the contrast betiveen subjective and objective as of the degree of reality of the subject to which reference is made. 
to use "Worth" as equivalent to Eigenwerth and to confine "Value" to Wirkungswerth. It is a pity that we have not also a convenient word to describe subjective value, as distinguished from objective. Kant, it will be remembered, attempted a three-fold classification-Fancy Value, Market $\mathbf{V}_{\mathbf{g l u e}}$, and Dignity or Worth ${ }^{2}$. The first of these may be said to correspond to subjective value, whether intrinsic or instrumental, while the third corresponds to objective "Eigenwerth." But there seems to be a class still wanted to include those objective "Wirkungswerthe" which are not economic. If, for instance, Punishment is rightly valued as a means of Reformation, it can hardly be said that, so regarded, it has either a Fancy Value, a Market Value, or an intrinsic Dignity. Here, then, we seem to have a problem for the word-fanciers.

1 Metaphysic of Ethics, Section II. Kant's terms are "Marktpreis," "Affectionspreis," and "Würde" I may remark here that the terms írawerá and rimea, as used by Aristotle (Eth. Nicom., I., rii., 1, and MFag. Mor., I., ii.), correspond very closely to the "Wirkuugswerthe" and "Eigenwerthe" of Ehrenfels-durákss in the same connexion being almost equivalent to Utilities. But Aristotle's use of these terms is not uniform. Cf. Stewart's Notes on the Nicomachean Ethics, Vol. I., p. 152. 